Journal of Educational Research in Developing Areas (JEREDA)

Vol. 1. Issue 3, Pp. 192-201, 2020

http://www.jeredajournal.com

E-mail: info@jeredajournal.com

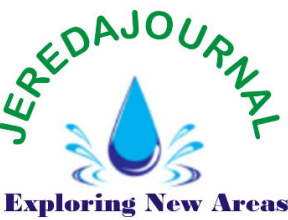

Research Article DOI: https://doi.org/10.47434/JEREDA.

eISSN: $2735-9107$

\title{
SOCIOECONOMIC STATUS ON ACADEMIC PERFORMANCE AMONG PRE-SERVICE TEACHERS OF KANO STATE COLLEGE OF EDUCATION AND PRELIMINARY STUDIES, KANO, NIGERIA
}

\section{Abubakar Garba}

General Education Unit, Kano State College for Education and Preliminary Studies, Kano, Nigeria

Email: indabo35@gmail.com

(i) https://orcid.org/0000-0002-0896-3982

Received: $3^{\text {rd }}$ October, 2020; Revised: $13^{\text {th }}$ October, 2020; Accepted: $15^{\text {th }}$ October, 2020

\begin{abstract}
Introduction: Education is a powerful and uncontrolled cornerstone that a nation can build towards the creation of responsible citizens, particularly young people for the future.
\end{abstract}

Purpose: It is therefore very important for this study to be conducted among them in order to find out that their parents' socioeconomic status have a positive or negative effect on their academic performance.

Methodology: The study adopted an ex post-facto form of research design. The target sample for this study consisted of 120 second year pre-service teachers selected using simple random sampling from three units of the School of General Education. Descriptive statistics of mean and standard deviation were used and $t$-test (Independent sample) was used to test hypotheses at 0.05 alpha level of significance. It was analyzed after the data was collected.

Results: The results of the study showed that students with a high socio-economic status had a high academic output compared to students with a middle socio-economic status. On the other hand, there was also a significant difference between middle and low socio-economic status students in terms of their academic success.

Recommendations: Government should also provide ample reading resources and a driving learning environment for less privileged pre-service teachers so that they can also compete favorably with their peers with higher socio-economic status.

Keywords: Parental Economic Status, Academic Achievement, Pre-Service Teacher

Cite paper as:

Crossref Garba, A. (2020). Socioeconomic status on academic performance Cited-by among pre-service teachers of Kano state college of education and preliminary studies, Kano, Nigeria. Journal of Educational Research in Developing Areas, 1 (3), 192-201. https://doi.org/10.47434/JEREDA.1.3.2020.192.

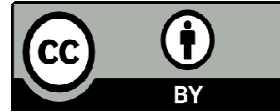

Copyright (c) 2020 The author(s) of this article retain(s) the copyright.

\section{PUBLIC INTEREST STATEMENT}

The findings of the study will help the parents, teachers and other statakeholders in providing sufficient funding and learning materials that will boost their children academic performance, as the education nowadays has a positive link with the level of parents socio-economic status and involvements, with the need to produce authenticated, qualified and professional tearchers for future generation. 


\section{INTRODUCTION}

The socio-economic status of a family will influence the behaviour of children and influence their expectations. Families with a high socio-economic status often have more success in preparing their children for education, since they typically have access to a wide range of high-quality child care, books and home-based learning opportunities for their young children. They also have easy access to information on their children's well-being as well as on physical, emotional and cognitive development (Ojo \& Yilma 2010), and Ojo and Yilma also noted that parents face major challenges in all socioeconomic groups when it comes to providing their children with adequate care and education, and these challenges are more pronounced in poor families. This is because, in many situations, when there is a lack of basic needs, parents must give priority to housing, food, clothing and health care, in terms of educational materials and books as luxury goods. They added that poor families may also have inadequate or limited access to community resources that promote and support children's growth and school preparedness. They also argued that these disadvantages may adversely affect family decisions about the growth and learning of their children. This scenario, according to Ojo and Yilma, could also expose infants in poor families to a greater risk of entering unprepared kindergarten schools, unlike their peers from rich families.

The question of socio-economic status (SES) remains of great concern to students academic achievement. Socioeconomic status is a sociological classification that describes the close relationship between someone's relative wealth and their social status. Socioeconomic status can be seen as a division of citizens by wages, which can be daily, weekly, monthly and yearly. It may also be attributed to schooling and the work class. Okunniyi (2004) described three distinct socio-economic groups or statuses common to many countries. They are:
1. Upper / Higher Class: It is made up of rich businessmen and senior government officials, among others.

2. Middle class: it consists of skilled employees, professionals and middle class government workers.

3. Lower class - consisting of small merchants and low-income government officials.

Socioeconomic status in general can be understood in these three (3) categories, that is, high socio-economic status, medium socio-economic status and low socio-economic status, to illustrate the three areas in which a family or person can fall. Any or more of the three variables: income, education and occupation, can be analyzed and measured at the point where the family or individual is included in one of those classifications. The responsibility to educate the child is always in the care of the parents. This is consistent with the regular testimony of the sociologist that education can be an instrument of social change taught at home. It is not surprising to see that the parent socioeconomic base may have an impact on the academic performance of children at school. However, not every child comes from a family that could provide them with the required educational resources to ensure their academic success. Consequently, the socio-economic status of the parent plays an important role in the provision of these educational services and appears to have the greatest impact on the child's educational outcomes (Vellymalay, 2012).

Educators, trainers and scholars have long been involved in researching factors that effectively lead to quality academic performance. Variables that effectively contribute to high-quality academic performance are both developed within and outside the school. These variables can be referred to as learning factors, socio-economic factors, peer groups and school factors. Socioeconomic factors may include parental education, parental income, financial and material support for parents, language, parental involvement in child education and peer-to-peer education in school 
settings. However, socio-economic status, in addition to other school variables, is a major indicator of students' good academic performance at school. Parental socio-economic status influences children's upbringing and, as a result, their actions and predisposition towards their goals and aspirations in life. There is a broad range of literature that highlights the effect of socio-economic status on academic performance among students from different perspectives of educational institutions, such as the study conducted by Ogunshola and adewale (2012) on the "effect of parent socio-economic status on academic performance of students in selected schools" in Edu-Lafiagi, Kwara State, Nigeria. Researchers looked at the relationship between home-based environmental influences and student academic success in selected secondary schools in the Kwara State Region of local government. Samples were collected from one hundred and eighty (180) students randomly selected from three secondary schools. The questionnaire was used to gather relevant information on the demographic details of the students (age, gender), the socioeconomic status of the parents, the educational background and qualifications of the parents and the health status of the respondents. The four variables measured and statistically evaluated were: the socio-economic background of the parent, the educational background of the parent, the educational qualifications of the parent and the health status of the student. The data collected was analyzed using the frequency count as a percentage of variables such as age and sex. Hypotheses were analyzed using t-test, variance analysis (ANOVA) and pairwise turkey test comparison at 0.05 significance level. The outcome has shown that parental socio-economic status and parental socio-educational experience have a direct effect on the academic performance of students.

Suleman, Aslam, Shakir, Akhtar, Hussain and Akhtar (2012) while children with a high socio-economic status display better academic performance compared Volume 1, Number 3 to those with a weak socio-economic status, they have shown weak and unsatisfactory academic performance. Saifi (2011) investigated the effect of socio-economic status on student performance. Results have shown that parental education, job and home facilities have an effect on the student's achievement. In his study, Hashim (2012) compared the socio-economic status of learners with their Englishlanguage scores in the most recent public analysis. He found that higher-income learners are consistent with low-income learners. He suggested that the positive correlation of high family income with higher levels of English proficiency among students may be due to their early education in private English middle schools compared to lower-income students. In order to support the above argument, the following theory is needed.

Parental investment theory on socio-economic status: Investment theory has become one of the best known hypotheses on the socio-economic status of parents. The adherent of the investment model emphasizes the advantages that the child receives in development due to the financial and well-being of the family. Under the scheme, families with high economic income will be able to invest in children's growth, while economically disadvantaged families will not be able to invest in children's development because they need to invest in families with basic needs. To highlight the fact that economically well-off families are able to support children's learning through advanced training and tutoring, they are also able to provide ample food, housing, clothing and health care and, finally, families with high economic capital are living in advantageous regions that further support the growth of children's skills (Shala, 2016).

\section{STATEMENT OF THE PROBLEM}

The perception of the interrelated nature of various human variables, such as socio-economic status, has increased in recent years. It is widely agreed that parental socio-economic status has a 


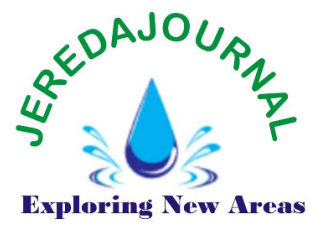

result of the high and low socioeconomic status between Kano State College of education and Preliminary Studies pre-service teachers.

2. There would be a large difference in academic performance from the medium and low socio-economic status of Kano State College of Education and Preliminary Studies pre-service teachers.

3. The high and medium socioeconomic status of the academic performance difference between Kano State College of education and Preliminary Studies preservice teachers would be important.

\section{METHOLOGY \\ Research Design}

The study was carried out using the ex post-fact research design method to investigate the effect of the parent socio-economic status on academic performance among the pre-service teachers of the Kano State College of Education and Preliminary Studies. The Ngwagu (2005) ex-post-fact study design is a systematic empirical inquiry in which the researcher does not have direct influence over independent research. The goal of the ex-post-facto research design is to identify variables that tend to be closely related to such behaviours, incidents, prevalence or conditions. Expost-facto design is considered suitable for this study because it is both practical and versatile. It allows the researcher to obtain the original data from the respondents themselves and describes the present conditions in their natural family settings. Consequently, the fact that the independent variable under analysis has already taken place cannot be tracked or manipulated by the researcher.

\section{Population and Sample}

The population of this study was year 2 pre-service teachers of one hundred and twenty (120) selected by random sampling techniques from three units of the School of General Education, namely: Adult and Non-Formal Education 
(ANF), Primary School Education (PES) and Early Childcare Education (ECCE). Looking at the study population, the researcher decided to take the full 120 years 2 of the pre-service teachers as his study sample, with the justification that he had enough time to carry out the study, that the study required fewer financial issues, that there was also enough research assistants and, ultimately, that the researcher wanted to generate a reliable and justifiable result, and thus a reasonable opportunity to participate.

\section{Instrument for Data Collection}

The Parental Socioeconomic Status Questionnaire (PSESQ) developed by Niles (1981) was used with little adaptation to accommodate study respondents. The questionnaire consists of two sections $A$ and $B$ Section $A$ of the questionnaire, which sought information on student demographic data such as: student class, school name, parent occupation, and parents with the highest monthly income, while section B requested information. The procedure followed when data were collected from the General Education School Evaluation Officer and collected the academic progress report of 120 pre-service teachers during the 2017/2018 session. The researcher then moved to room 92, which is a lecture at $12: 00$ p.m. On Monday 11/02/2019, where the researcher's lectures were conducted wisely, the researcher demanded the assistance of the lecturer and three class members for the administration of the questionnaire, and the researcher was also granted permission to administer the questionnaire.

The Parental Socioeconomic
Status Questionnaire (PSESQ) was

developed by Niles (1981) and the instrument was accurate before use. This means that the instrument designed by Niles was used, with little modification, to suit the study respondents. In doing so, the researcher introduced three research experts, two from the Kano State College of Islamic and Legal Studies and one from the Kano State College of Education and Preliminary Studies, all were educational psychologists. Reliability of the Parental Socioeconomic Status Questionnaire (PSESQ) Niles (1981) from which the PSESQ was adapted claimed to measure the same objectives as the current analysis, thus found it to be highly compatible internally and recommended to be reliable for use. The researcher also sent three research experts, two from the Kano State College of Islamic and Legal Studies and one from the Kano State College of Education and Preliminary Studies.

\section{Method for Data Analysis}

Depending on the nature of the analysis, two different statistical approaches have been used to analyze the data obtained as follows. Descriptive mean and standard deviation statistics used and $t$-test (Independent sample) used to test hypotheses at 0.05 alpha levels of significance.

\section{RESULTS}

The results were structured in line with the following assumptions:

Hypotheses 1: There would be a major difference in academic performance as a result of the high and low socio-economic status between Kano State College of education and Preliminary Studies PreService Teachers.

Table 1: Showing Mean, Standard Deviation, Mean Difference, and $t$ value of High and Low Socioeconomic status

\begin{tabular}{lllllll}
\hline Students & N & Mean & SD & MD & df & t-value \\
\hline High SES & 40 & 67.52 & 16.86 & & & \\
Low SES & 40 & 58.16 & 16.99 & & & \\
\end{tabular}

*significant at 0.05 level

Volume 1, Number 3 
In table 1 , the SD, mean and $\mathrm{MD}$ $[(M=67.52,58.16), \quad(S D=16.86,16.99)$ and $(M D=9.39)$ ] respectively have a high and low socio-economic status with respect to the academic performance of pre-service teachers. The obtained tvalue $(2.47 / 78)$ was more significant than the table value at 0.05 (1.99). The result shows that pre-service teachers with high socio-economic status have a high academic performance compared to pre-service teachers with low socioeconomic status. On the basis of the findings, the researcher should conclude that the first hypothesis is retained.

Hypothesis 2: There would be a large difference in academic performance from the medium and low socio-economic status of Kano State College of Education and Preliminary studies pre-service teachers.

Table 2: Showing Mean, Standard Deviation, Mean Difference, and t- value of Middle and Low Socioeconomic Status.

\begin{tabular}{lllllll}
\hline Group & N & Mean & SD & MD & df & t-value \\
\hline Middle SES & 40 & 55.12 & 10.05 & & & \\
Low SES & 40 & 58.16 & 16.99 & & 78 & 0.97 \\
\hline
\end{tabular}

The second hypothesis is rejected as t-value $(0.97 / 78)$ was marginal at 0.05 (1.99) levels of significance. Average scores of pre-service teachers from families with a middle socioeconomic status were obtained (55.12), which is less than the average score (58.16) of pre-service teachers from families with a low socio-economic status. Likewise, the SD and MD of the same group were found $[(S D=16.86$, 16.99) and ( $M D=9.39)]$ respectively.

Hypotheses 3: There would be a substantial difference in academic performance as a result of the high and middle socio-economic status of Kano State College of Education and Preliminary Studies pre-service teachers.

Table 3: Showing Mean, Standard Deviation, Mean Difference, and $t$ value of High and Middle Socioeconomic

\begin{tabular}{lllllll}
\hline Group & N & Mean & SD & MD & df & t-value \\
\hline High SES & 40 & 67.52 & 16.86 & & & \\
Middle SES & 40 & 55.12 & 10.05 & & & \\
\hline
\end{tabular}

**significant at 0.01 level

The last hypothesis of the present study is also accepted, as the obtained tvalue $(3.99 / 78)$ was found to be significant at 0.01 (2.63) level of significance. The average score obtained from the pre-service teachers was high socio-economic status (67.52), which is higher than the average score (55.12) of the pre-service teachers in the middle socio-economic status family. Likewise
High SES Middle SES (67.52) (55.12) Mean SD and MD scores in the same group were $[(S D=16.86,10.05)$ and $(M D=12.39)$ ] respectively. Thus, the results of this study show that preservice teachers with a high socioeconomic status have a high academic performance compared to pre-service teachers with a medium socio-economic status. 


\section{DISCUSSIONS}

Table 1 indicates that SD and MD were of high and low socio-economic status with respect to the academic performance of students. The obtained tvalue $(2.47 / 78)$ was found to be more important than the tabulation value at 0.05 (1.99). The results showed that preservice teachers with a high socioeconomic status had a high academic performance compared to pre-service teachers with a low socio-economic status based on the researcher's findings, thus recognizing the first hypothesis. The finding of the hypothesis go hand in hand with the results of Suleman, Aslam, Shakir, Akhtar, Hussain and Akhtar (2012), which found that children with high socio-economic status had higher academic performance compared to those with low socio-economic status, and had low and unsatisfactory academic performance. Thurayya (2017) also found that socio-economic factors had an effect on the academic performance of students in Nigeria. Similar results are made in Kenya, where high-income parents take their children to boarding schools, while low-income parents take their children to public primary schools, and private primary schools perform more academically than most public primary schools in Kenya.

The study also showed that the second hypothesis (there would be a major difference in the academic performance of pre-service teachers from medium to low socio-economic status) was rejected because the t-value $(0.97 / 78)$ was found to be marginal at 0.05 (1.99) of significance. Average scores of pre-service teachers from families with middle socio-economic status have been reported (55.12), which is less than the average score (58.16) of pre-service teachers from families with low socio-economic status. The results were also consistent with the findings of Hashim(2011). In the study of the socioeconomic status of learners and their English-language scores in the most recent public review. He found that higher-income learners are consistent with low-income learners. Musa (2018) also concluded that the socio-economic Volume 1, Number 3 factors of the parents did not extend to adolescents and that academic achievement in the rural area sample was not sufficient. He said that it was not so much the economic status of the parents, but rather the zeal and dedication of the learners. In certain ways, the educational standard and the reading materials in the home make it clear to the scaffolding learners that poor performance in school does not rely solely on parents who have a socioeconomic status, but rather on the influence of the age of the gangs, the zeal and the role of the learners.

The findings of the present study (there would be a substantial difference in the academic output of pre-service teachers with a high and middle socioeconomic status) was also retained because the t-value obtained (3.99/78) was found to be significant at 0.01 (2.63) level of significance. Average scores of pre-service teachers have been found to have a high socio-economic status (67.52), which is more than the average score (55.12) of pre-service teachers in the middle socio-economic family. Accordingly, the results of this study showed that pre-service teachers with a high socio-economic status have a high academic performance compared to preservice teachers with a middle socioeconomic status. Similarly, the findings are consistent with the results of Ogunshola \& Adewale's study (2012) on the effect of the socio-economic status of parents on the academic performance of students in selected schools. The result indicated that the socio-economic status of parents had a significant impact on the academic performance of students. While Farooq, Chaudhry, Shafiq and Berhanu (2011) indicated, in their report, factors affecting the quality of academic performance of students in Pakistan, that family characteristics, such as socioeconomic status, are significant predictors of good academic performance of learners, in addition to other school factors and student factors.

\section{RECOMMENDATIONS}

The following recommendations were made: 


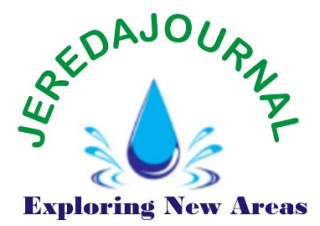

out if similar results can be obtained.

\section{CONCLUSION}

This study focused on how students. Parents should also provide their children with sufficient funding for academic issues. This will boost their children's academic performance.

2. Parents regardless of their socioeconomic status and educational attainment, the study recommends that they should actively participate in the academic affairs of their children. Not just for financial purposes.

3. The study also recommends that teachers understand that teaching is a work of conscience and that they should treat students as their own children; that they aim to fulfill the social and psychological academic needs of students that motivate them to learn better.

4. There is a need for time-to - time workshops and seminars organized by the College Management on different forms of teaching techniques, such as the transition of teaching methods from the Teacher Center Method of Teaching to the Student Center Method of Teaching. Thus, all classes of students will learn better, regardless of the socioeconomic background of the preservice teacher.

5. Further research is needed to study the problem in a large sample and to carry out similar studies with other schools of education in the state of Kano. The research examined only the socio-economic status of students with academic performance; further studies should be done on other socio-economic status factors with other variables that affect students' academic performance. The study focused on the atmosphere of the College of Education. Hence there is need similar research to be carried out at the University settings to find

Volume 1, Number 3 parental socioeconomic status influence academic performance of preservice teachers, regardless of the present poor financial status of many parents of preservice teachers, hence, the paper employed parental investment theory. The theory emphasizes the advantages the child receives in development due to the financial and well-being of their family in addition to their zeal of learning, the financial challenges (socioeconomic status background) is what affect the academic performance of the learners base on the study. The present study proves that pre-service teachers with a good socio-economic status had excellent academic performance compared to pre-service teachers with poor socio-economic status.

\section{Conflicts of Interest}

The author declares no conflict of interest.

\section{Acknowledgment}

I appreciate all colleagues who supported me technically when the study was being carried out. I appreciate the effort of Hajjiya Rabi Muhammad Abdullahi, the Deputy Provost, Shehu Abubakar, Hassan Ismail, Hassan Dauda, Kabiru Muhammad and the examination officer, School of General Education Kano State College of Education and Preliminary Studies, the lecturers and the class representative who assisted me in the administration of the questionnaire.

\section{Author Bionote}

Abubakar Garba hails from Indabo town, a village under Wudil local Government, Kano State. Attended Tarauni special primary School and GSS Tarauni. He earned a Bachelor Degree of Education in Hausa Language. $\mathrm{He}$ is presently Assistant Lecturer in the Department of Education. Kano State College of Education and Preliminary Studies (KASCEPS). His area of research 
interest is psychological construct. He could be reached on email:indabo35@gmail.com, and phone Number+2348035919266;

09073073956

\section{Disclaimer Statement}

I hereby declared that this paper is my own and autonomous work although consultation of other study with the same variables or little differences were made to have a guide. All sources and aids used have been indicated and acknowledged. Full details are given in the reference list which also containing an access date. This work has not been submitted to any other examination authority.

\section{References}

Academic Progress report (2019). Result analysis of 120 Pre-service Teachers of the year 2017/2018 Session. Retrieved from Directorate of examination and record keeping, Kano state college of education and Preliminary studies.

Farooq, M. S., Chaudhry, A. H., Shafiq, M. \& Berhanu, G. (2011). Factors affecting students' quality of academic performance a case of secondary school level. Pakistan Journal of Quality Management, VII, 174-197. http://www.pu.edu.pk/images/journ al/1qtm/pdf.

Niles, S. F. (1981). Social class and academic achievement: A third world Reinterpretation. Comparative Education Review 25 (3), 419-430.

Nwagu, E. K. N. (2005). Method of research and how to write and what to Write-step-By-step: Guide to educational research proposal and report: A publication of the Institute Of Education. University of Nigeria Nsukka.

Hamid, M. O. (2011). Socio-economic characteristics and English language achievement in rural Bangladesh. Bangladesh eJournal of Sociology, 8 (2), 31-51.

Hashim, Z. (2012). Comparative study of learners' socio-economic status with academic achievement in senior

Volume 1, Number 3 secondary school students of Kano metropolitan. International Journal of Human Studies, 3(6), 30-40.

Musa, G. (2018). Relationship between aspects of socioeconomic factors and academic achievement in Malaysia. Journal of Educational Sociology, 7 (3), 30-45.

Ogunshola, A. W. (2012). The relationship between socioeconomic status (SES) and early development: Empirical findings and theoretical perfectives. Journal of educational Psychology Research, 40 (4), 209-220.

Ojo, B. J. S., \& Yilma, T. (2010). Comparative study of the influence of the home background on students' achievement in mathematics in Bensihangul Gumuz Regional state of Ethiopia. An Unpublished Phd.thesis University of Ethiopia.

Okunniyi, O. N (2004). The Influence of family background on students' introductory technology achievement of junior secondary school in Abeokuta south LGA of Ogun State. An Unpublished M.Ed. Thesis, University of Nigeria Nuskka.

Vellymalay, S. (2012). Parental involvement at home: Analyzing the influence of parents' socioeconomic status. Studies in Sociology of Science, $\quad 3 \quad(1), \quad 1-6$. https://doi.org/10.3968/j.sss.19230 18420120301.2048.

Saifi, S., \& Mehmood, T. (2011). Effects of socio-economic status on student's achievement. International Journal of Social Sciences \& Education, 1 (2), 119128.

Thurayya, M. (2017). Socioeconomic factors influencing student academic performance in Nigeria some explanation from a local survey. Journal of Human development Research 1(2), 20-30.

Suleman, Q., Aslam, H. D., Shakir, M., Akhtar, S., Hussain, I., \& Akhtar, Z. (2012). Effects of family structure on the academic performance of students at elementary level in 
district Karak, Khyber Pakhtunkhwa (Pakistan). Journal of Sociological Research, 3 (2), 25-32.

Shala, A. (2016). The relationship between socioeconomic status (SES) and early development: Empirical findings and theoretical perfectives. International Multidisciplinary Journal Ethiopia, 5, 156-166.

Suleman, Q., Aslam, H. D., Shakir, M., Akhtar, S., Hussain, I., \& Akhtar, Z. (2012). Effects of family structure on the academic performance of students at elementary level in district Karak, Khyber Pakhtunkhwa (Pakistan). Journal of Sociological Research, 3 (2), 25-32.

Thurayya, M. (2017). Socioeconomic factors influencing student academic performance in Nigeria some explanation from a local survey. Journal of Human development Research 1(2), 20-30.

Vellymalay, S. (2012). Parental involvement at home: Analyzing the influence of parents' socioeconomic status. Studies in Sociology of Science, 3 (1), 1-6. https://doi.org/10.3968/j.sss. 19230 18420120301.2048. 